\title{
Carbonless Transportation and Energy Storage in Future Energy Systems
}

\author{
G.D. Berry, A.D. Lamont
}

January 17, 2001

U.S. Department of Energy

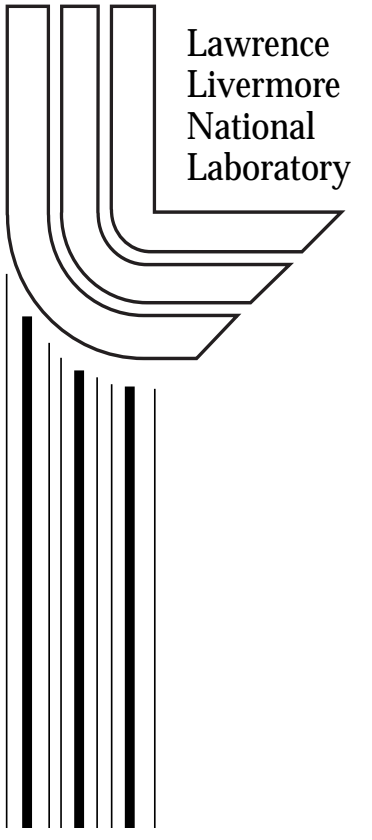




\section{DISCLAIMER}

This document was prepared as an account of work sponsored by an agency of the United States Government. Neither the United States Government nor the University of California nor any of their employees, makes any warranty, express or implied, or assumes any legal liability or responsibility for the accuracy, completeness, or usefulness of any information, apparatus, product, or process disclosed, or represents that its use would not infringe privately owned rights. Reference herein to any specific commercial product, process, or service by trade name, trademark, manufacturer, or otherwise, does not necessarily constitute or imply its endorsement, recommendation, or favoring by the United States Government or the University of California. The views and opinions of authors expressed herein do not necessarily state or reflect those of the United States Government or the University of California, and shall not be used for advertising or product endorsement purposes.

This work was performed under the auspices of the U. S. Department of Energy by the University of California, Lawrence Livermore National Laboratory under Contract No. W-7405-Eng-48.

This report has been reproduced directly from the best available copy.

Available to DOE and DOE contractors from the

Office of Scientific and Technical Information

P.O. Box 62, Oak Ridge, TN 37831

Prices available from (423) 576-8401

http://apollo.osti.gov/bridge/

Available to the public from the National Technical Information Service

U.S. Department of Commerce 5285 Port Royal Rd., Springfield, VA 22161

http://www.ntis.gov/

OR

Lawrence Livermore National Laboratory Technical Information Department's Digital Library http://www.llnl.gov/tid/Library.html 


\title{
Carbonless Transportation and Energy Storage in Future Energy Systems
}

\author{
Gene D. Berry and Alan D. Lamont
}

By 2050 world population is projected to stabilize near 10 billion. Global economic development will outpace this growth, achieving present European per capita living standards by quintupling the size of the global economy - and increasing energy use, especially electricity, substantially. Even with aggressive efficiency improvements, global electricity use will at least triple to 30 trillion $\mathrm{kWh} / \mathrm{yr}$ in 2050. Direct use of fuels, with greater potential for efficiency improvement, may be held to 80 trillion $\mathrm{kWh}$ (289 EJ) annually, 50\% above present levels (IPCC, 1996). Sustaining energy use at these or higher rates, while simultaneously stabilizing atmospheric greenhouse gas levels, will require massive deployment of carbon-conscious energy systems for electricity generation and transportation by the mid $21^{\text {st }}$ Century. These systems will either involve a shift to non-fossil primary energy sources (such as solar, wind, biomass, nuclear, and hydroelectric) or continue to rely on fossil primary energy sources and sequester carbon emissions (Halmann, 1999). Both approaches share the need to convert, transmit, store and deliver energy to end-users through carbonless energy carriers.

\subsection{Carbonless energy carriers}

Electricity is the highest quality energy carrier, increasingly dominant throughout the world's energy infrastructure. Ultimately electricity use can expand to efficiently meet virtually all stationary energy applications, eliminating stationary end-use carbon emissions. This approach is unlikely to work in transportation, however, due to the high cost and low energy density of electricity storage. Chemical energy carriers, such as hydrogen, can more effectively serve transportation fuel and energy storage applications, offering much higher energy density at lower cost. Electrolytic hydrogen, extracted from steam with renewable energy, stored as a high pressure gas or cryogenic liquid, and reconverted to electricity in fuel cells and or used to power hydrogen vehicles, will reduce emissions from both transportation and electric generation. Renewable resources and modular electrolytic technology also permit decentralized hydrogen production, circumventing distribution issues and barriers to market entry. In contrast, sequestrationbased fossil-fueled systems must achieve economies of scale by relying on centralized production and hierarchical transmission and distribution of electricity, hydrogen fuel, and carbon (dioxide).

Renewable and fossil approaches may ultimately turn out to be complementary. Use of renewable sources would limit the sequestration burden to modest quantities using the most cost effective methods and reliable disposal sites. Previous analyses have concluded renewable electricity will be cost effective in combination with dispatchable carbonless 
energy sources (i.e. hydroelectric, fission, and biomass), to minimize energy storage (Union, 1992; Kelly, 1993). Dispatchable carbonless sources only generate a fraction of current electricity, however, and are likely to be limited on the scale of burgeoning demand (Schipper, 1992; Fetter, 1999). A future role for biomass, in particular, may be restricted due to competing uses for land, water, and perhaps other agricultural inputs (Smil, 1998). An alternative to expanding fission, hydropower, and biomass is to use modest fossil electric generation and carbon sequestration as a complement to wind and solar energy. An integrated hydrogen transportation sector complements renewable systems both by providing a large, but flexible, use for excess renewable electricity and enabling dual-use of hydrogen fuel as utility energy storage and transportation.

This chapter surveys energy storage and hydrogen vehicle technologies, analyzing the integration of these technologies into increasingly renewable electricity and transportation sectors. The implications for greenhouse gas reduction strategies are examined using an aggressive efficiency scenario for the United States in 2020, the latest time horizon for which detailed sectoral projections have been made.

\subsubsection{Conventional energy storage technologies}

Low capital cost, but inefficient, gas-fired peaking plants are used to meet demand fluctuations in present utility systems. Demand fluctuations can also be met using energy storage to shift electric generation to more cost-effective times of day. Utility storage is employed today, in small amounts, using established principles of mechanical energy storage: elevated water or compressed air.

Hydroelectric pumped storage is the most widespread and mature technology, however the theoretical energy density of pumped hydro is quite low requiring 3.7 tonnes $(\sim 1000$ gallons) of water traversing $100 \mathrm{~m}$ of elevation to deliver $1 \mathrm{kWh}$. Pumped hydroelectric plants are consequently most viable on a large scale. The largest pumped hydro facility in the world today uses Lake Michigan and an artificial lake averaging $85 \mathrm{~m}$ of elevation. It has a peak generating capacity of $2000 \mathrm{MW}$ delivering up to $15,000,000 \mathrm{kWh}$ over a period of $\sim 12$ hours, supplying the equivalent electric demand of $\sim 1-2$ million people. Roundtrip efficiencies approach $70 \%$. Presently $2 \%$ of electric demand is met by pumped hydro systems (Howes, 1991).

Two disadvantages of hydroelectric energy storage appear in the context of future energy systems. The large scale nature of hydroelectric storage indicates little if any cost savings will exist for electric distribution systems connected to a pumped hydroelectric facility. Finally, in the context of solar or wind intensive energy systems it seems unlikely that sufficient sites could be found in convenient locations (i.e. where natural formations provide low per $\mathrm{kWh}$ storage costs) to contribute more than a minor role in overall 
energy storage. River-fed reservoir hydroelectric capacity is probably best used to offset seasonal variations in solar or wind electric generation.

Compressed air energy storage (CAES) is also a reasonably mature approach, though only employed in a few sites worldwide. Energy density is about 50 times greater than hydroelectric storage. Air compressed to 100 atmospheres of pressure in a 20 gallon volume contains $1 \mathrm{kWh}$ of energy. This energy density is still quite low, however: the same volume of compressed natural gas (CNG) contains nearly 100 times more energy. CAES is economic at larger scales (100-200 MW), relying on natural formations for low cost storage capacity, limiting widespread implementation. The compressed air can be run through turbines to generate peak electricity, although the heat of expansion must be supplied by thermal storage or fuel. For economic reasons, interest is greatest in applying CAES if additional fuel is burned with the precompressed air, enabling smaller turbines to match peaks in electric demand. In this application, however, the majority of the energy from a CAES system actually comes from fuel rather than compressed air (Gordon, 1995). CAES systems are also not the most efficient method of gas-fired electric generation, and their greatest benefit is reducing the cost of generation capacity, rather than energy storage per se. CAES would have little to offer carbonless energy systems which do not rely much on fossil fuels, but do require renewable energy storage. Widespread application of CAES in a greenhouse gas context would require either carbon sequestration, or the use of carbonless fuel (i.e. hydrogen) produced elsewhere. The capacity for compressed air storage in CAES systems would be probably be more valuable as compressed hydrogen storage in the context of carbonless energy systems. Leakage has not been a difficulty when storing town gas (a mixture containing hydrogen) in underground caverns near Paris, France (Howes, 1991).

\subsubsection{Advanced energy storage technologies}

Advanced energy storage technologies, in contrast to conventional energy storage, are characteristically modular, highly engineered systems without the scale and location constraints of pumped hydroelectric or compressed air storage. Approaches to energy storage include thermochemical (chemical couples) and thermal (phase change materials), mechanical (flywheels), and electrochemical (batteries and electrolytic fuel production).

Thermochemical energy storage approaches capitalize on the high energy density of chemical energy storage and the use of low cost and abundant materials. Thermal energy can be stored in reversible chemical reactions (e.g. $2 \mathrm{SO}_{3} \leftarrow \rightarrow 2 \mathrm{SO}_{2}+\mathrm{O}_{2}$ or $\mathrm{CH}_{4}+\mathrm{H}_{2} \mathrm{O}$

$\leftarrow \rightarrow \mathrm{CO}+3 \mathrm{H}_{2}$ ) in which the reactants are transmitted though a "heat pipe" loop between thermal source and end-use over distances up to 100 miles (Vakil, 1978). For stationary 
applications, heat can be stored cheaply in the enthalpy of common materials (water, oil, or molten salts).

While thermochemical and thermal storage are expected to be low cost, the thermal energy stored is not as valuable as electric or fuel energy. The chief disadvantage of thermal energy storage per se is thermodynamic. Unlike electricity or fuels, thermal energy "leaks" continuously, and in proportion to the useful work which can be extracted (determined by the Carnot cycle). Today, large amounts of energy are used as heat for low temperature space and water heating, some of which could arguably be saved through judicious use of thermal energy storage. However, thermodynamics again present a disadvantage as future space and water heating needs could be supplied very efficiently using heat pumps. As a method of reducing carbon emissions, thermal energy storage is likely to be most useful at modulating solar power production to more effectively meet late afternoon peaks or nighttime electricity demands, using solar thermal electric plants (De Laquil, 1990).

Electricity can be stored reasonably compactly and very efficiently as kinetic energy in flywheels. Flywheel energy storage is in the early stages of commercialization, and is targeted at uninterruptible power supplies (UPS), where the value of energy reliability far exceeds the value of energy. Flywheels can spin at very high velocities (10,000-100,000 $\mathrm{rpm})$ in vacuum using magnetic bearings. They offer high efficiency $(90 \%+)$ charging and discharging, low power related costs $(\sim \$ 100 / \mathrm{kW})$ and the prospects of very long equipment lifetime (Post, 1973). A $1 \mathrm{kWh}$ flywheel module may weigh $10 \mathrm{~kg}$ and occupy 2 liters. Flywheel feasibility has advanced substantially with the advent of very strong and light carbon fibers and other composite materials. On the other hand, all of this specialized technology and materials (e.g. magnetic bearings to eliminate friction and provide rotor stability) can lead to high costs per unit of energy stored. Cost estimates are currently $\$ 100 / \mathrm{kW}$ and $\$ 600 / \mathrm{kWh}$ of storage capacity, although costs may fall to $\$<200 / \mathrm{kWh}$ (Post, 1993) in mature mass production. Flywheel sizes are relatively small (1-300 $\mathrm{kWh})$ and are probably best placed near end-users in the electricity system, easing the burden on distribution, providing peak power and reliability, and making future energy systems uninterruptible.

The chief alternative to flywheels is electrochemical energy storage. Batteries are heavier, and less efficient (70-80\% turnaround efficiency), but more compact than flywheels. Batteries have lower capital costs $(\$ 100-\$ 200 / \mathrm{kWh})$, but also a much lower cycle life (1000's of cycles) placing in some doubt their role in bulk power storage. The availability of mineral resources for common battery materials (lead, nickel, cadmium etc.) is likely insufficient (Bjorn, 1998) for globally significant amounts of energy storage (e.g. 24 hour storage, roughly 100 billion $\mathrm{kWh}$ would require 1-2 billion tonnes of battery 
materials) in future electricity systems. The most compelling energy application of batteries is efficient electrification of moderate range (100-200 miles) passenger vehicles, assuming battery mass and cycle life can be improved sufficiently.

Less well known than batteries is a closely related alternative: electrolytic fuel production. Electrolysis differs from battery storage in that the electrodes are not chemically changed during electrolysis and do not store energy as in batteries. Energy is instead stored in the chemical fuel produced. A number of electrolytic fuels have been proposed (e.g. lithium, aluminum, and zinc) whose technology is closely related to metalair (oxygen) batteries. One advantage of electrolytic fuels is the decoupling of power (electrodes and electrolyte) and energy (fuel) functions which are combined in batteries. This reduces the capital cost of achieving high power or large storage capacity. Electrolytic fuels offer potentially rapid refueling and lower weight than conventional batteries, especially when using atmospheric oxygen is as a reactant.

Hydrogen has been considered for decades as a universal electrolytic fuel and energy carrier (CRC, 1977; Bockris, 1980; Winter, 1988; Ogden, 1989; Ogden, 1993). Historically, the feasibility of hydrogen has been limited by the fuel economy of passenger vehicles and the corresponding weight of onboard fuel storage systems to achieve good travel range. Recent advances in composite materials, as well as hybrid electric vehicles have resolved these issues, enabling future hydrogen vehicles 2-3 times more fuel efficient than those envisioned 20 years ago. As a renewable energy carrier electrolytically produced from abundant water, hydrogen is capable of fueling all transportation sectors indefinitely. A spectrum of hydrogen storage methods allow hydrogen systems to be tailored to the economics of individual applications. Electrolytic hydrogen fuel is expected to have low capital costs of production (electrolysis), storage (compressed gas, cryogenic liquid, or chemical storage), and utilization (hybrid electric engines or fuel cells). Estimates in a utility context are $\$ 500-1000 / \mathrm{kW}$ and $<\$ 5 / \mathrm{kWh}$. The chief disadvantage is that the cumulative process efficiencies of each of step in hydrogen systems lead to roundtrip efficiencies of $30-40 \%$, roughly half that of more direct storage technologies. Decentralization may offset this to some extent, potentially making waste heat available for space and water heating.

It is clear from the above discussion that energy storage technologies are best suited to different roles. Flywheels can improve transmission and distribution reliability, storing and delivering electricity perhaps twice daily. At the opposite end of the temporal spectrum, buffered hydroelectric generation may be most useful in adjusting to seasonal electric supply and demand variations. Batteries most useful contribution would be enabling high efficiency short range transportation. The most important role of thermal energy storage technology is probably allowing solar energy to contribute to nighttime 
electricity production. Electrolytic hydrogen can serve as a bulk energy storage and universal transportation fuel, even if somewhat energy intensively.

The usefulness of each technology will depend on how well these roles meet the needs of future electricity supply mixes which make increasing use of intermittent electric generation, as well as an evolving transportation sector potentially powered directly by electricity or indirectly through electrolytic fuels.

\subsubsection{Transmission technologies}

Transmission technology advances can also play a role in carbonless energy systems, potentially easing local renewable resource constraints by enabling solar and wind energy to be harnessed at greater distances from urban load centers. Transmission is expected to incrementally improve by going to higher voltages, with DC transmission replacing AC transmission lines for long distances. In the longer term high power and perhaps underground cryoresistive and/or superconducting transmission lines could ultimately allow for wholesale long distance electricity transmission, reducing energy storage needed for seasonal and day/night variations around the globe. Another futuristic option may be transmission of energy by relay satellite, similar to proposed satellite or lunar solar power (Hoffert, 1998). Capital costs of transmission are typically moderate relative to both electricity distribution and renewable electricity production. In future energy systems, however, full utilization of electric transmission capacity may become more difficult if large, but intermittent, solar or wind energy facilities are distant from population centers.

An alternative to electric transmission is hydrogen transmission by pipeline or cryogenic tanker, just as natural gas is transmitted today. Pipeline systems offer some buffer capability reducing their sensitivity to short-lived fluctuations in supply or demand. Hydrogen pipelines have been in operation for decades and it is possible for today's natural gas pipelines to transport hydrogen, albeit at reduced pressure and higher cost than today's natural gas (CRC, 1977; Bockris, 1980; Winter, 1988; Ogden, 1989; Ogden, 1993). For equal investment, new hydrogen pipelines also deliver substantially more energy than electric transmission lines, although the conversion losses (electric energy to hydrogen energy and back to electricity) may counter this advantage. The chief factors determining the efficacy of transmitting energy as hydrogen are the scale of energy demand necessary to justify pipelines, and the fraction of demand for transportation fuel $v s$. electricity.

In the near future, energy storage and perhaps transmission improvements can improve electricity distribution and reliability as electricity markets become deregulated, but this

will not impact overall energy use or emissions substantially. In the intermediate term, an increasing reliance upon intermittent (solar, wind), and/or less flexible (nuclear) 
electricity sources will at some point require significant energy storage, as distinct from power storage. This storage will be needed to match non-dispatchable electricity sources with varying electric demands (Iannucci, 1998). Finally, energy storage as electrolytic fuels can extend the reach of carbonless energy sources to the transportation sector. This is especially important since the transportation sector is the highest value use of fossil fuels (Berry, 1996), the largest source of carbon emissions, and the least amenable to sequestration approaches.

\subsection{Transition paths toward carbonless energy}

Lawrence Livermore National Laboratory (LLNL) has developed a network optimization model (Figure 1) to examine these three stages of integrating renewables into utilities (reliability, intermittent intensive electric systems, and carbonless transportation). By constructing and analyzing model scenarios of future electricity and transportation systems attempts we quantify the characteristics of transition paths to carbonless utilities and transportation. The model calculates the economically optimum energy system to meet scenarios of electricity and/or transportation demands, arriving at the desired system structure in terms of energy supply sources, conversion technologies, and storage capacities. It simultaneously determines optimal operation of the system components using, patterns of electricity demand (Iannucci, 1998), transportation fuel demand, energy available from solar and wind production, and capacities of long and short term hydrogen storage technologies. A more detailed model description and table of key assumptions used to generate these scenarios is given in Appendix A. 


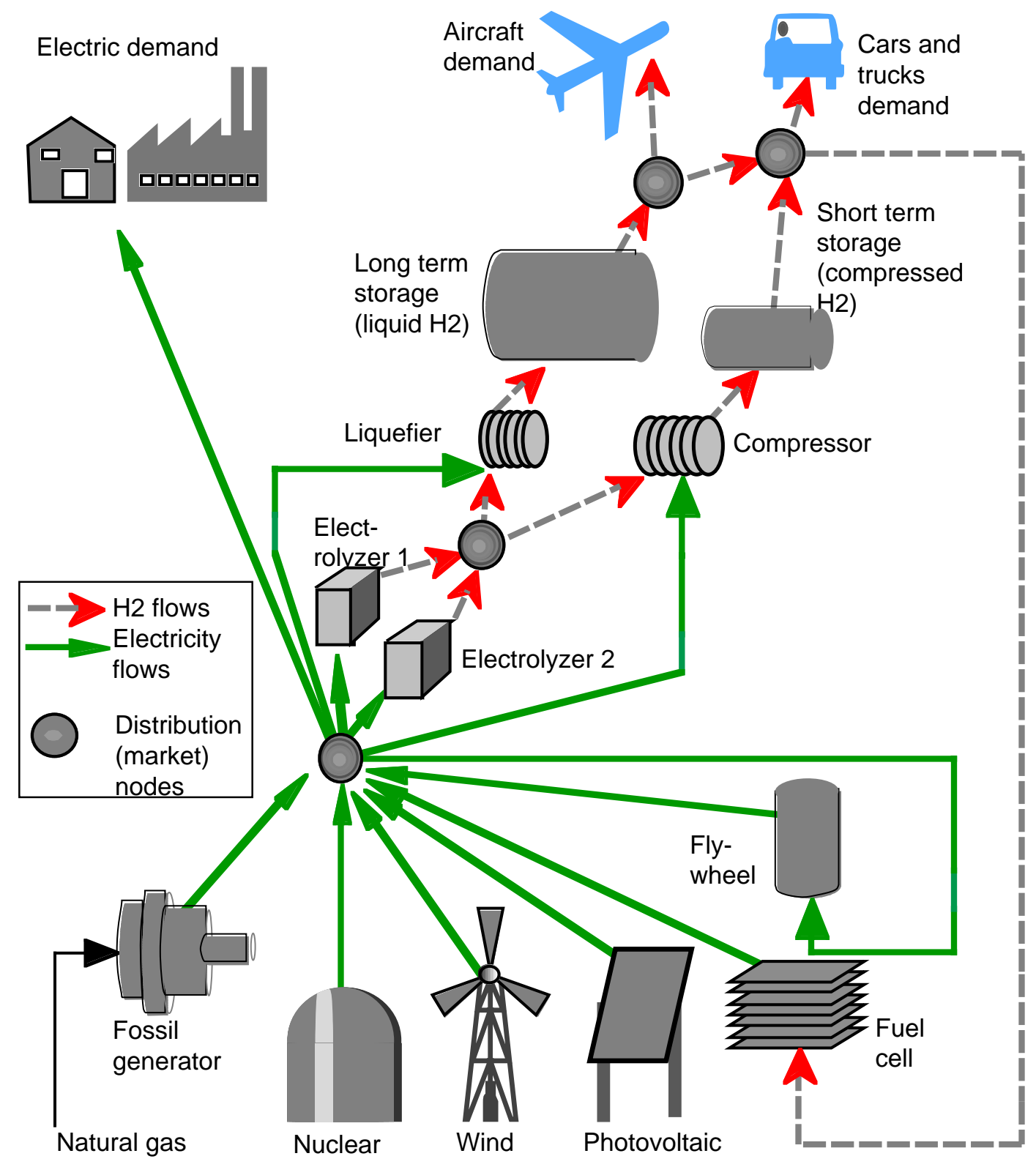

Figure 1: Schematic of a coupled utility electric generation and transportation system using nuclear, fossil, and renewable primary energy sources, with electricity and hydrogen as energy carriers. 
Although there are many transition paths to a carbonless future, we wish to try to identify paths that are economically and strategically advantageous. Using the model discussed above, we have evaluated a broad range of possibilities, using various levels of nuclear, natural gas and renewable generation in combination with a transportation sector using natural gas and/or hydrogen in various amounts. In order to explore a representative example for which data was readily available, we chose to design scenarios based on U.S. Energy Information Agency projections of electricity and transportation demands of the United States in 2020 (EIA, 2000). Under this scenario, within two decades, the United States will demand roughly 5 trillion kWh of electricity ( $1 / 3$ of world demand) and 4.6 trillion $\mathrm{kWh}$ of transportation fuel.

A subset of model results are shown as points in Figure 2 Each point corresponds to the projected cost of an electricity and transportation fuel system which can achieve the given level of overall carbon emissions from both sectors. These scenarios trace a transition which is efficient in terms of reducing carbon emissions for minimum cost, the efficient frontier. From an economic perspective an optimum emission reduction path should fall on this frontier since any other approach will cost more, have higher emissions, or both. 


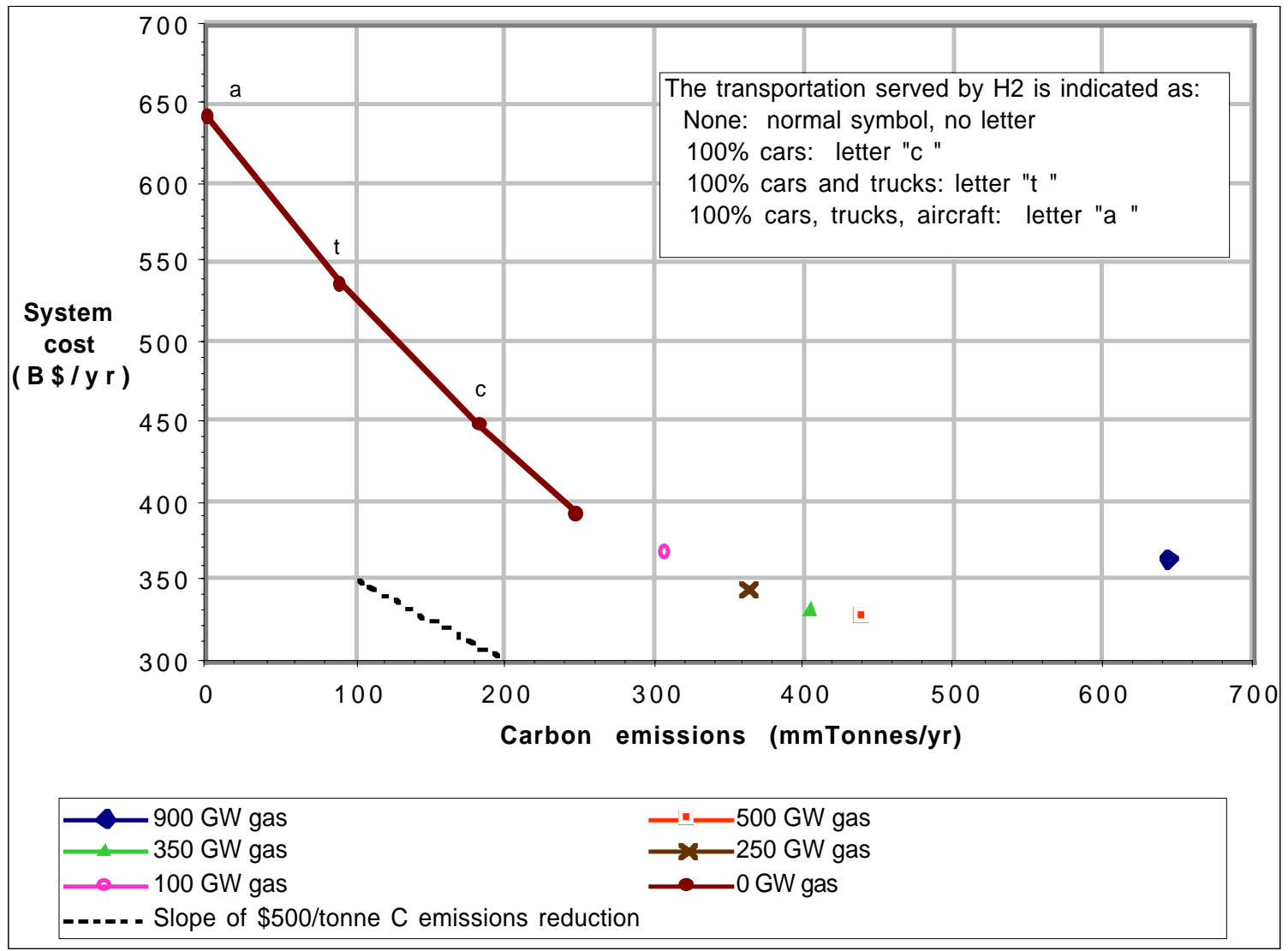

Figure 2: The efficient frontier for reducing U.S. 2020 overall carbon emissions Moving from right to left, natural gas generation capacity is reduced and replaced by renewable generation.) Carbon emissions can be reduced to around $250 \mathrm{~mm}$ Tonnes by displacing natural gas electric generation. Further carbon reductions are achieved by replacing natural gas fueled transportation with hydrogen-fueled transportation. Each case meets 5 trillion $\mathrm{kWh}$ of electricity demand and 4.6 trillion $\mathrm{kWh}$ of fuel demand and includes 100 $G W$ of nuclear capacity in addition to the gas-fired generation capacities indicated.

Figure 3 shows hourly variations in electricity demand and generation for a ten day period representative of selected cases along the efficient frontier. These cases illustrate the changes in generation patterns and structure along the efficient frontier as natural gas is displaced by renewables and hydrogen transportation is ultimately phased in. 
Figure 3: A series of dispatch diagrams from the model. These show the effect of changing the systems configuration along the efficient frontier. Each figure show the dispatch of the electric generating devices over a ten day period starting at the $150^{\text {th }}$ day of the year (end of April) serving the projected U.S. electricity grid in 2020.

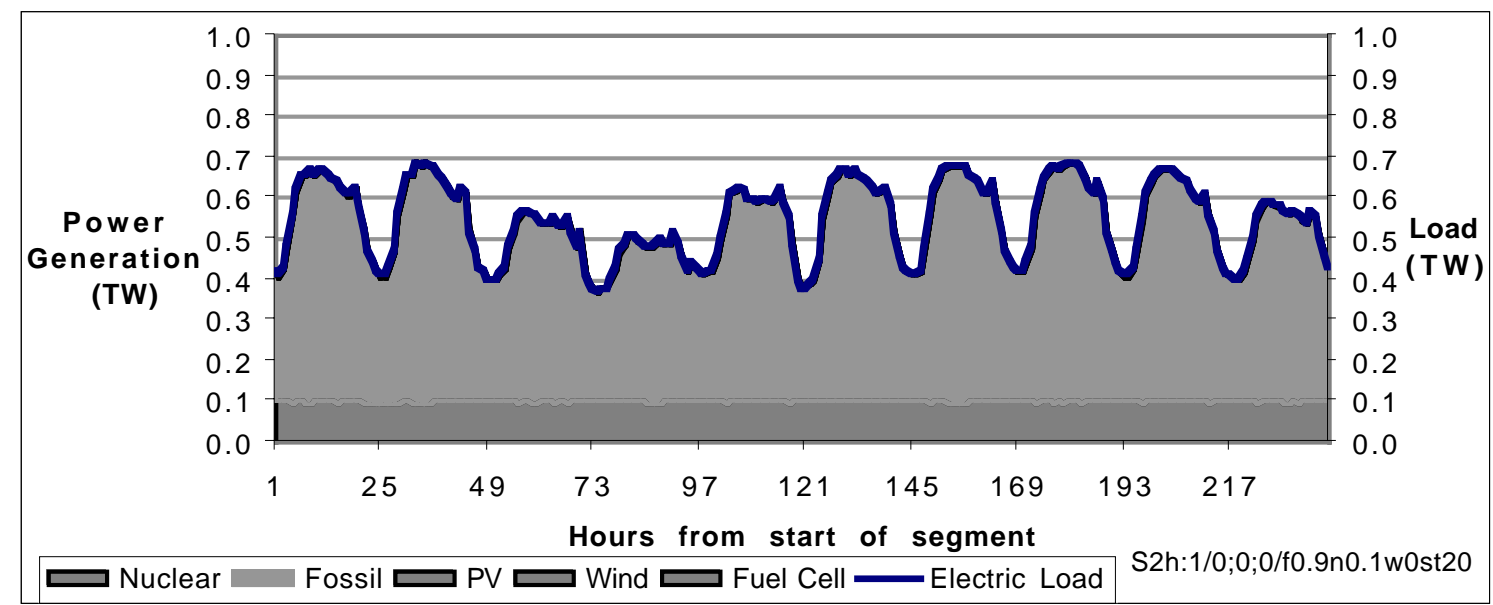

(A) dispatch of an all gas and nuclear utility system. It simply follows the electric load. Note that all transportation is fueled by natural gas (not shown).

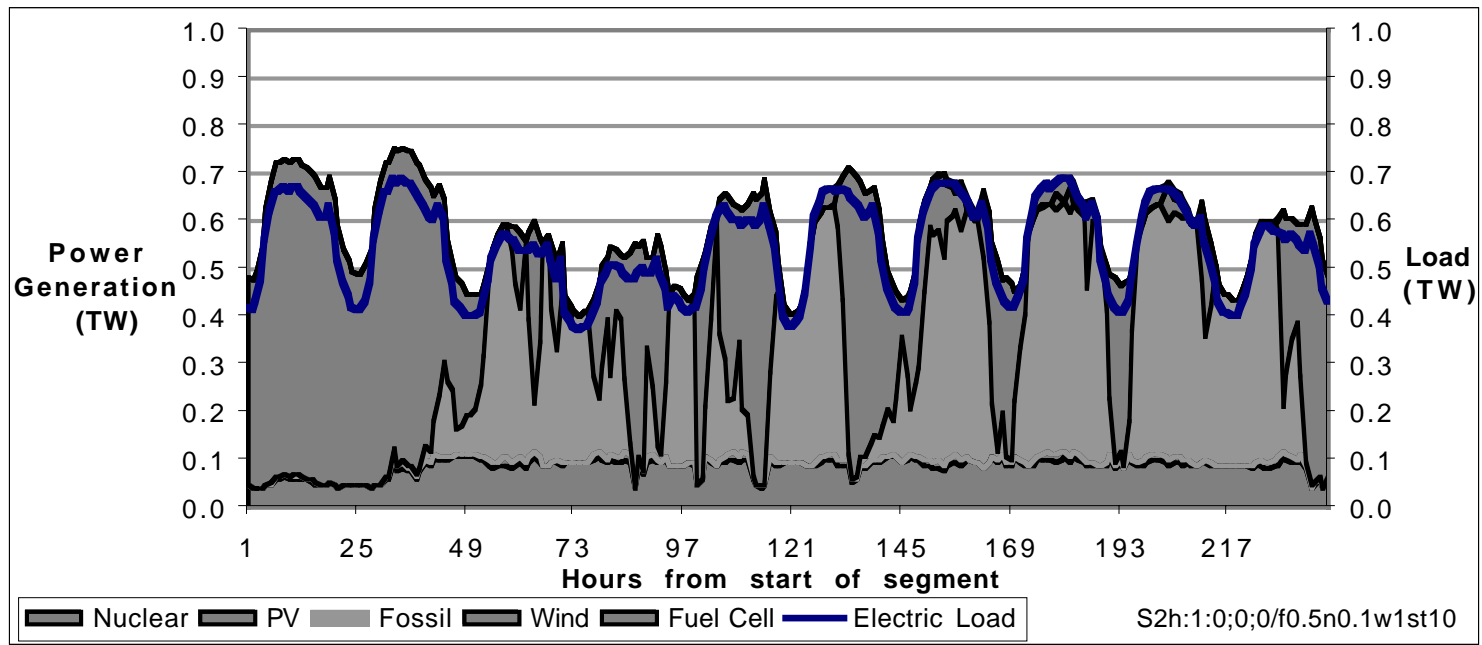

(B) Electric generation system with $0.5 \mathrm{TW}$ of gas capacity blended with wind and tiny amount of solar generation. This is the least cost system of all the model scenarios. The fuel cell is used occasionally to meet the peaks in the electric load. The wind generation often exceeds the electric demand by a small amount to provide energy needed to run the fuel cell. 


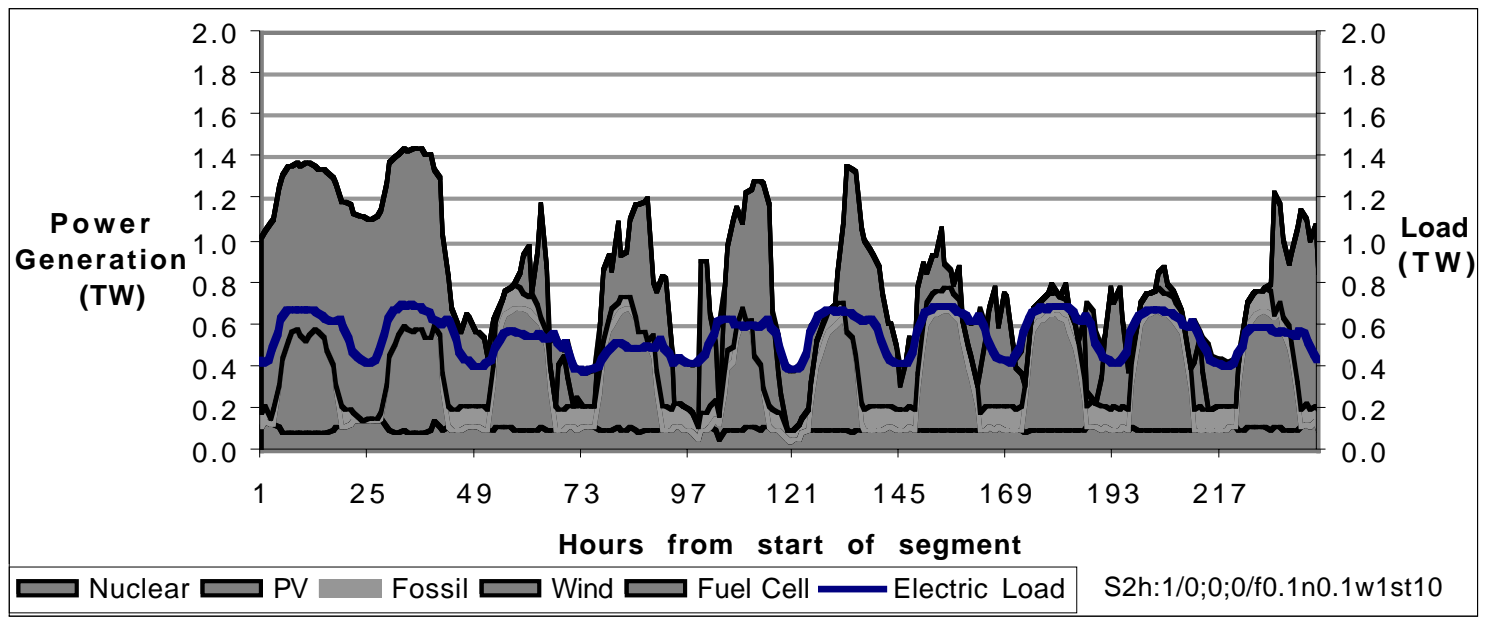

(C) System with $0.1 \mathrm{TW}$ of gas capacity. The fuel cell is called upon more often to serve larger portions of the load on windless evenings and mornings. Larger amounts of wind are required to provide the hydrogen needed for the fuel cell. The wind capacity has reached its practical limit of $1.0 \mathrm{TW}$ capacity. . Although there is $1.0 \mathrm{TW}$ of wind capacity in this system, it is not always fully dispatched. For example at around hours 10 and 30 only about $0.8 \mathrm{TW}$ are dispatched even though at these hours there is fully 1.0 TW available. This is because it is not economic to add enough electrolysis, compression, and liquefaction to accept the full output of the wind, PV, and nuclear simultaneously since such high outputs only occur occasionally during the year. At hour 121 the fuel cell displaces the gas generator. This is an imperfection in the algorithm's solution which occurs a few instances per year.

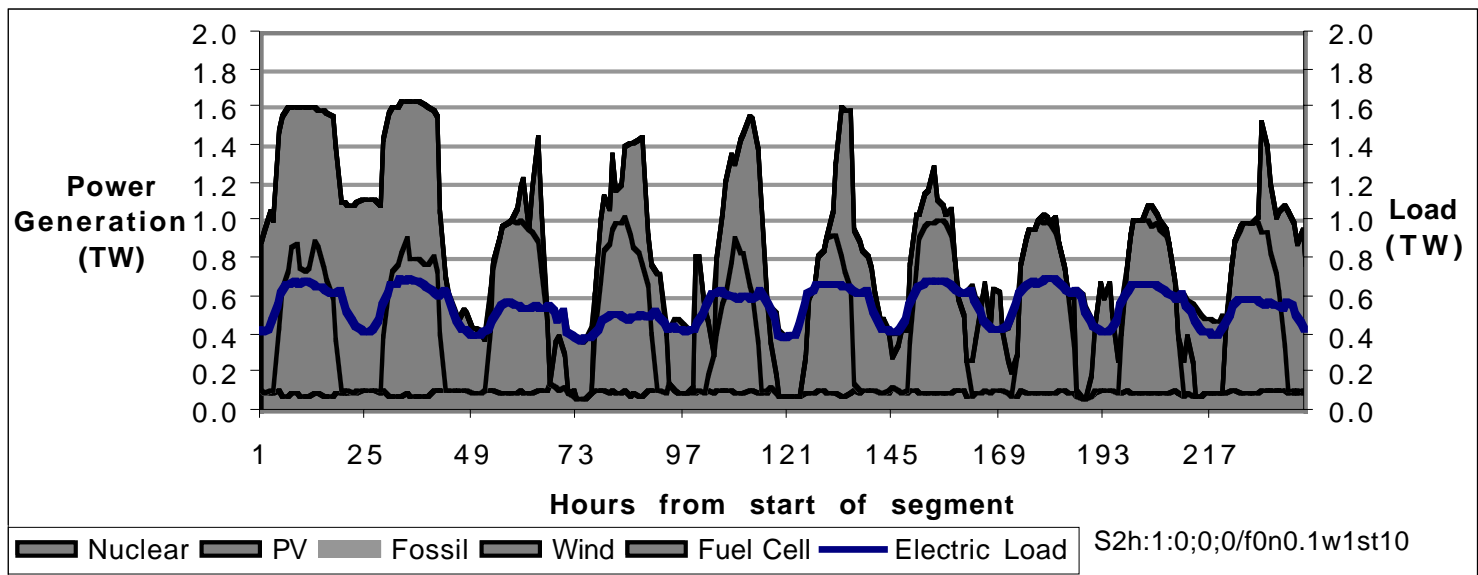

(D) Carbonless energy system serving electric demands and fueling hydrogen cars.

Since the wind capacity had reached it limit in the previous case, all additional energy to make energy for the fuel cell and the cars must come from $P V$. 


\subsubsection{High efficiency use of low carbon fuels}

Our starting point is a scenario that efficiently uses natural gas and nuclear electric generation while transportation is fueled by natural gas (lower right point in Figure 2. In assessing different carbon reduction strategies, there is generally consensus that improved efficiency and fuel switching to natural gas are "no regrets" measures. To take this into maximum account, we have therefore chosen to measure scenarios using solar and wind electricity against a "no regrets" technically advanced carbon-conscious scenario fueled by natural gas.

Our 2020 U.S. reference scenario relies essentially on very efficient use of natural gas. Hydroelectric and nuclear power (hereafter combined for simplicity and referred to as nuclear) provide nearly $20 \%$ of electricity and $10 \%$ of the generating capacity of a 1000 GW U.S. electricity system. Natural gas fuels the remaining $80 \%$ of U.S. electricity generation at $57 \%$ efficiency, in addition to the all the automobiles, trucks, and aircraft in the U.S. transportation sector. The natural gas infrastructure is assumed to meet all these demands as efficiently as theoretically possible. Fuel cycle greenhouse gas emissions are neglected and natural gas leakage is assumed to be reducible to negligible levels. 250 million light-duty vehicles in the U.S. are assumed to achieve an average fleet economy of $80 \mathrm{mpg}$ through the use of lighter and more aerodynamic automobiles. Driving is assumed to rise only slightly to $14,000 \mathrm{miles} / \mathrm{yr}$. Natural gas at refueling stations is priced at $\$ 6.93-\$ 8.31 /$ GJ (equivalent to $\$ 0.83-1.00 /$ gallon of gasoline). Natural gas for utility electric generation is priced somewhat lower at $\$ 5.54 / \mathrm{GJ}$.

Even with all the progress assumed in this scenario, U.S. electricity and transportation fuel use is projected to produce 642 million metric tonnes of carbon emissions in 2020 and cost roughly $\$ 350$ billion/yr. Rapid and full implementation of the "no regret" strategy, throughout the entire infrastructure, manages relatively moderate emission reductions relative to current levels (1000 mmtC/yr). Rising energy use driven by population and especially economic growth partially offset a near doubling of electric generation efficiency, a tripling of automobile fuel economy, and a near halving of the carbon intensity of fuels. Global emission targets consistent with stabilizing greenhouse gases at an equivalent doubling of carbon dioxide would limit worldwide gas fuel emissions to $4000 \mathrm{mmtC} / \mathrm{yr}$ (Fetter, 1999). An eventual U.S. target based on per capita share and adjusted to reflect transportation and utilities emissions alone would be $\sim 100$ $\mathrm{mmtC} / \mathrm{yr}$. Obviously, reducing carbon emissions to this level from the advanced fossil scenario (642 $\mathrm{mmtC} / \mathrm{yr}$ ) will ultimately require a massive shift from fossil energy to carbonless sources. 


\subsubsection{Displacing natural gas generation with renewables}

To efficiently offset the greatest amount of carbon emissions, direct displacement of gas generation with wind and solar electricity is likely to be the best first step. The gas fired electric generation sector is projected to account for substantially more emissions (394 $\mathrm{mmtC} / \mathrm{yr})$ than a natural gas transportation system $(248 \mathrm{mmtC} / \mathrm{yr})$ which also has more complex fuel infrastructure issues than electric utilities. Employing carbonless sources in the utility sector also circumvents the energy penalties of converting wind or solar electricity to transportation fuel.

This forms the basis of a "utilities first" approach, in which fossil electric generation is successively displaced by renewables and ultimately eliminated. Further emission reductions are accomplished by displacing natural gas transportation fuel with renewable hydrogen, first in automobiles, then freight trucks, and ultimately in aircraft. The corresponding sequence of scenarios are shown in Figure 2. The cost breakdowns (Figure 4) and energy flows (Figure 5) indicate the dramatic shifts in energy supply, storage, emissions, and marginal cost as carbon emissions are reduced, and ultimately eliminated, using the "utilities first" strategy. 


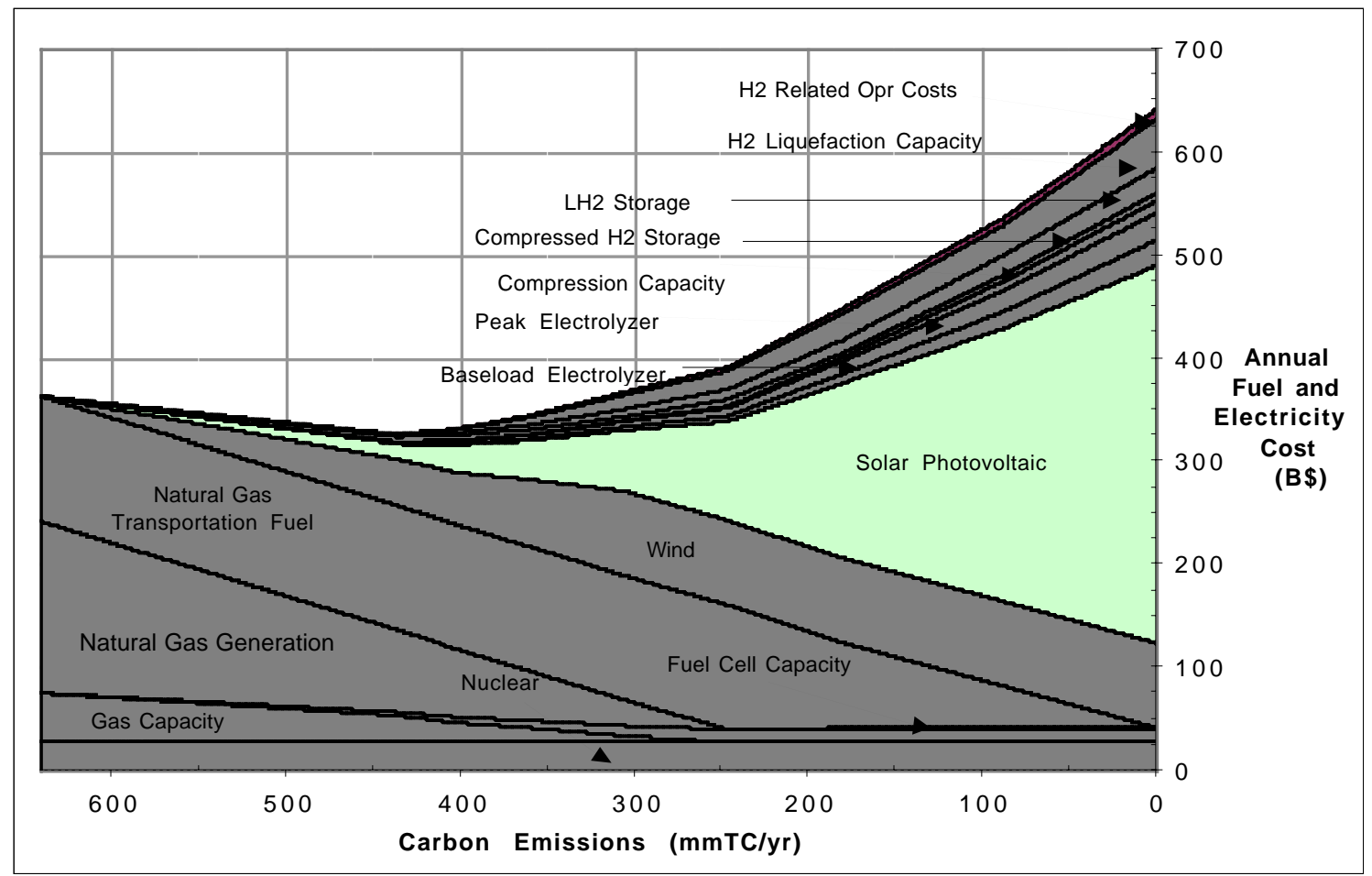

Figure 4: : Cost breakdown for electricity and transportation systems using the "utilities first" approach to reducing carbon emissions along the efficient frontier in Figure 2. 


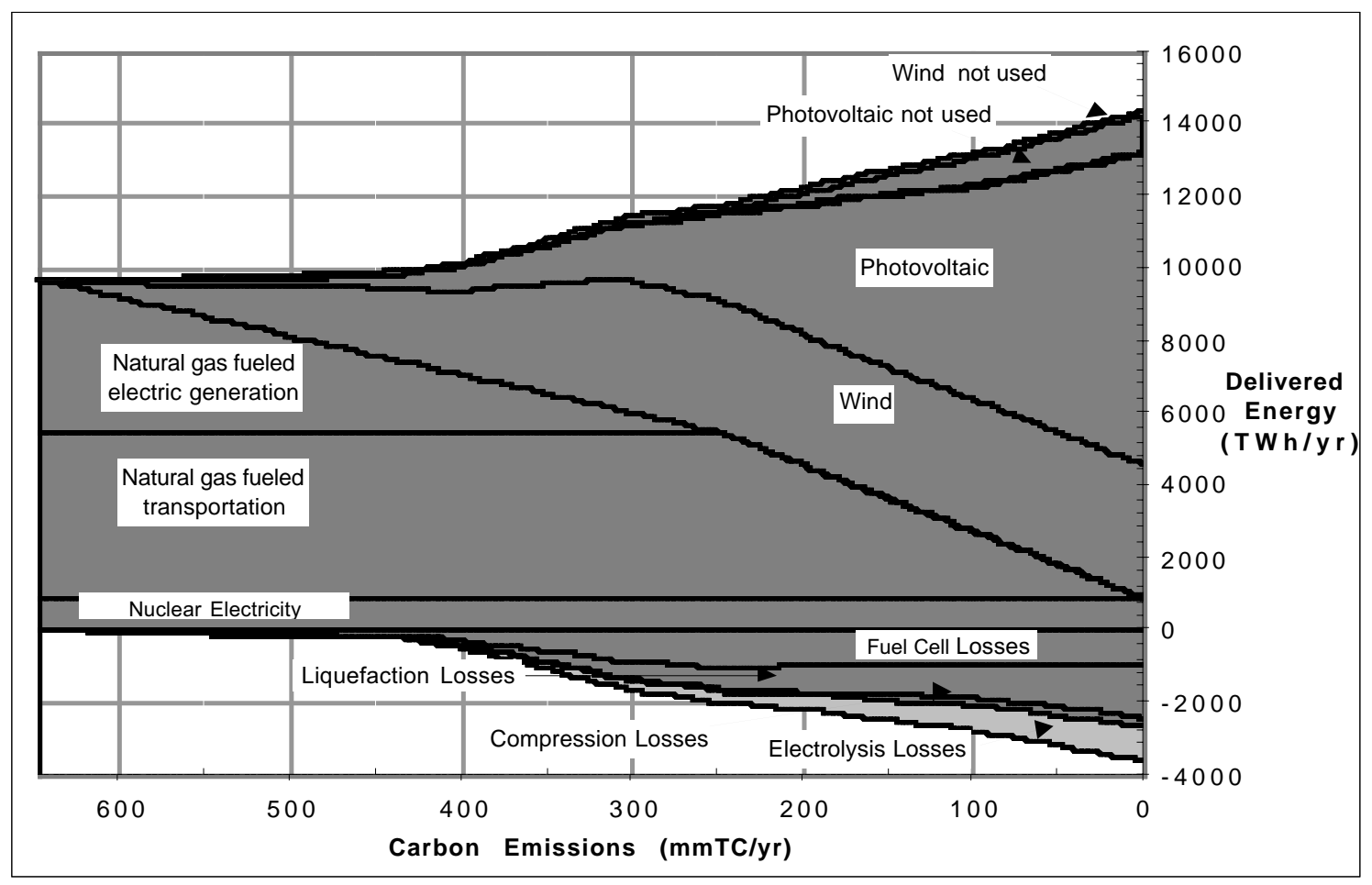

Figure 5: : Energy flows for electricity and transportation systems using the "utilities first" approach to reducing carbon emissions along the efficient frontier in Figure 2. 5000 TWh of electricity and 4600 TWh of transportation fuel are delivered for end-uses. As carbon emissions are reduced, natural gas is displaced from electric generation, then from transportation. Losses are shown for hydrogen production, storage, and reconversion to electricity in fuel cells.

\subsubsection{Integrating intermittent renewables}

Initially, displacing natural gas generation with low cost wind energy is projected to reduce emissions and system costs (Figure 2, $500 \mathrm{GW}$ scenario). Wind capacity can be fully absorbed by the electric grid, except during occasional nighttime hours of very low demand, and very high wind availability. Solar electricity will just begin to be cost effective, even though twice the cost of wind per kWh, augmenting generation during periods of higher (daylight) electric demand. Energy storage at this level of renewable penetration is minimal, accounting for roughly $2 \%$ of generation (similar to pumped hydro today). This storage essentially serves the same function as pumped hydro, reducing the cost of generating capacity. More than $95 \%$ of renewable generation will serve the grid directly, cost-effectively reducing total system emissions to $2 / 3$ of the U.S. 2020 reference case. Intermittent electricity, predominately wind, will account for $50 \%$ of the utility mix. 
Later scenarios (Figure 2, $350 \mathrm{GW}$ scenario) indicate integration issues increase the cost of emission reductions. Displacing more natural gas requires wind capacity levels near day-time peaks, as wind electricity costs much less than solar. At night wind capacity is high relative to demand, and must be stored, displacing natural gas only indirectly (and less efficiently) through fuel cells. As the mismatch between electric demand and wind generation grows, high cost solar electricity will cost-effectively contribute, flattening net electric demand patterns. This enables excess wind to be more cost-effectively used in electrolyzers, producing hydrogen. This hydrogen will be needed by fuel cells to meet peak demands in excess of the gas-fired capacity, accounting for roughly $5 \%$ of delivered electricity. Emissions are reduced to $404 \mathrm{mmtC} / \mathrm{yr}$ at a marginal cost of $\$ 150 /$ tonneC.

Reducing gas capacity further (Figure 2, $250 \mathrm{GW}$ scenario) limits the ability of fossil generation to compensate for seasonal mismatches between demand and renewable (principally wind) supply. This will substantially increase solar generation, which matches seasonal demand patterns well. In winter, when solar is only partially available, and short term hydrogen storage is not large enough to cover periods between windy days, energy intensive liquid hydrogen will be used extensively. Fuel cell generation will grow to $10 \%$ of delivered electricity, being required every windless night and cloudy day. Carbon emissions will fall to $362 \mathrm{mmtC} / \mathrm{yr}$ at a marginal cost of approximately $\$ 300 /$ tonneC.

Reducing emissions to $305 \mathrm{mmtC} / \mathrm{yr}$ (Figure 2, $100 \mathrm{GW}$ scenario) will raise the wind capacity to the assumed maximum of 1.0 TW (Schipper, 1992; Fetter, 1999). Additional displacement of natural gas will require increasing costlier solar capacity. Reduced gas generating capacity will also lead to greater fuel cell use (18\% of delivered electricity). On days when wind and solar generation coincide, hydrogen will be sent to long term hydrogen storage since compressor capacity is exceeded. Liquid hydrogen flow will grow relative to capacity. Relying increasingly on high cost solar generation is the chief factor contributing to a marginal cost of $\$ 400 /$ tonneC reducing emissions to $305 \mathrm{mmtC} / \mathrm{yr}$.

Removing natural gas generation entirely from the utility sector (achieving 248 $\mathrm{mmtC} / \mathrm{yr}$ ), will increase solar generation to levels above peak daytime demands, leading to routine storage of excess solar electricity as compressed hydrogen to power late afternoon fuel cell generation. Fuel cell generation will peak at $20 \%$ of total electric demand. A totally carbonless utility system will require 7 trillion $\mathrm{kWh}$ of carbonless generation to reliably deliver 5 trillion $\mathrm{kWh}$ of end-use electricity) eliminating utility emissions at a marginal cost of $\$ 400 /$ tonneC (Figure 2, $0 \mathrm{GW}$ scenario). Further carbon reductions must then come from the transportation sector, essentially fueled by additional solar power. 


\subsection{Hydrogen Transportation Technology}

U.S. transportation fuel use is projected to reach nearly 4.6 trillion $\mathrm{kWh}$, even if the Partnership for the Next-Generation of Vehicles (PNGV) succeeds in tripling automobile fleet fuel economy by 2020. Light-duty passenger vehicles will then account for approximately $25 \%$ of fuel use, aircraft for $35 \%$, and heavy trucks for $40 \%$. Fueling this demand with natural gas will produce direct carbon emissions of $248 \mathrm{mmtC} / \mathrm{yr}$.

It will be easiest for hydrogen to displace natural gas in the light-duty vehicle fleet first. Passenger vehicles are idle $90 \%+$ of the time, with fuel costs accounting for $5-10 \%$ of ownership costs. The development of hybrid electric cars and trucks and later fuel cell vehicles, make the prospect of achieving $80 \mathrm{mpg}$ equivalent fuel economy over the entire vehicle fleet quite likely by 2020 . This improved fuel economy is the single most important step in making hydrogen fueled vehicles viable, dramatically reducing refueling cost and the size, weight, and cost of onboard fuel storage.

Hydrogen vehicles are expected to require 5 gallons of gasoline equivalent $(5 \mathrm{~kg}$ hydrogen) for a cruising range of $\sim 400$ miles. Hydrogen fuel can be stored onboard using lightweight composite pressure vessels, similar to natural gas vehicles. Other onboard storage approaches include hydrogen absorption and release from high surface area metal powders at moderate pressures, as well as cryogenic liquid hydrogen tanks operating near ambient pressures. Both approaches have been demonstrated in Germany for over a decade. As composite materials have improved in strength and cost, pressure vessel hydrogen storage is becoming more attractive. Another option is to insulate pressure vessels for cryogenic hydrogen service, using compressed hydrogen for routine refueling (perhaps at home or work), and cryogenic liquid hydrogen refueling for occasional long trips. Multi-layer insulation would be sufficient to store liquid hydrogen onboard vehicles even if parked for weeks at a time. Such a hydrogen storage vessel (Aceves, 1998) is expected to be relatively compact $(100 \mathrm{~L})$, lightweight $(100 \mathrm{~kg})$, and low cost $(\$ 500$ 1000).

Hydrogen fueled freight-transportation differs substantially from light-duty passenger vehicles. A typical long-haul tractor-trailer truck travels $\sim 100,000$ miles/yr, so fuel costs are a much higher proportion of total costs. This high sensitivity to fuel cost is the chief reason trucks engines are so efficient today. In the future, fuel cost sensitivity will provide the incentive for compressed hydrogen storage onboard trucks. This can reduce hydrogen fuel cost substantially, as compressed hydrogen is less energy intensive to produce than cryogenic liquid hydrogen. $25-50 \mathrm{~kg}$ of hydrogen fuel onboard an 18 wheel tractor trailer would provide a range of 300 miles for a fuel economy equivalent to 6-12 mpg. Onboard storage of this hydrogen (at $5000 \mathrm{psi}$ ) will require a volume of $\sim 250-500$ gallons. A distinct advantage of hydrogen fueled trucks is the benefit to urban air 
pollution. Particulate, hydrocarbon, and carbon monoxide emissions would be eliminated, reducing, perhaps obviating, the need for onboard pollution control equipment. Hydrogen fueled tractor trailer trucks have been demonstrated in Japan.

Energy density considerations dictate that carbonless aircraft will have to be fueled with liquid hydrogen. From an emissions and energy perspective, cryogenic liquefaction of hydrogen fuel is not advantageous. Typically, liquefaction is very energy intensive, requiring up to $40 \%$ of the fuel energy in the hydrogen. It is also reasonably expensive, liquefaction plants are estimated to cost $\sim \$ 500 / \mathrm{kW}$, while hydrogen compressors can be one-fifth this cost. The two principal advantages of liquid hydrogen are its low weight and low capital cost of large scale storage. The liquid hydrogen infrastructure at Kennedy Space Center is roughly $1 / 10^{\text {th }}$ the scale required for a large civilian airport.

Liquid hydrogen has 1/3 the mass of jet fuel for equivalent energy, but nearly 4 times the volume. These characteristics can substantially reduce takeoff weight for cryogenically fueled aircraft, with the attendant advantages, at the cost of substantial changes in aircraft design. Calculations indicate (Winter, 1988) that hydrogen aircraft would likely use $10 \%$ less fuel for subsonic flight and 50\% less fuel for supersonic flight than fossil-fueled counterparts. Given the uncertainties surrounding future air travel and to be conservative in comparisons, these potential advantages were neglected in the scenarios involving liquid hydrogen aircraft.

\subsection{Displacing natural gas from transportation}

Eliminating carbon emissions from electric generation is only a partial step in the transition to carbonless energy systems. Further carbon reductions will require renewable fuel production, most likely hydrogen, given its universal applicability to all sectors of transportation. Fundamental energy balance indicates, however, that the overall costs of reducing emissions from transportation will likely be higher than reducing emissions from the utility sector. A kWh of renewable electricity delivered for end-use displaces at least $1.75 \mathrm{kWh}$ of fossil fuel (natural gas). Alternatively that $\mathrm{kWh}$ of electricity would displace only $0.63-0.83 \mathrm{kWh}$ of gas use though electrolytic hydrogen substitution in transportation. This basic factor is the underlying reason for the higher cost of carbon reduction in the transportation sector. Using solar electrolytic hydrogen, fueling 250 million passenger vehicles can reduce carbon emissions from 248 to $182 \mathrm{mmtC} / \mathrm{yr}$ at a cost of $\$ 850 /$ tonneC. Displacing natural gas from freight transportation can reduce emissions to $90 \mathrm{mmtC} / \mathrm{yr}$, increasing marginal cost only slightly to $\$ 950 /$ tonneC, due to the lowered capacity factor of hydrogen production equipment driven by the solar patterns availability. Eliminating emissions from transportation completely requires displacing natural gas from aircraft with energy intensive liquid hydrogen, raising costs substantially to $\$ 1150 /$ tonneC. 


\subsubsection{Joint carbon reduction from utilities and transportation}

An alternative to the "utilities first" carbon reduction strategy just outlined is to undertake emission reductions from utilities and transportation sectors in tandem. Figure 6: shows model scenario results in addition to those in previous cases in which transportation and utility reductions are undertaken together. In the figure sets of points with the same fossil and nuclear capacity (100 GW nuclear in all cases) are shown together as a line. Points on the line indicate the cost and emissions with various hydrogen transportation options (e.g., none, cars only, cars and trucks, or cars, trucks and aircraft). The first point in each line is the case of no hydrogen transportation. These all fall on the efficient frontier. Interestingly, once low levels of fossil generation are achieved, scenarios that include some hydrogen transportation also fall on the efficient frontier of lowest marginal cost, or very close to it. Overall emissions and costs between scenarios are within $5 \%$ over this range of carbon emissions. This suggests displacing natural gas from the entire (250 million) light-duty vehicle fleet will have costs comparable to reducing natural gas from utility generation when achieving emissions levels below $350 \mathrm{mmtC} / \mathrm{yr}$. 


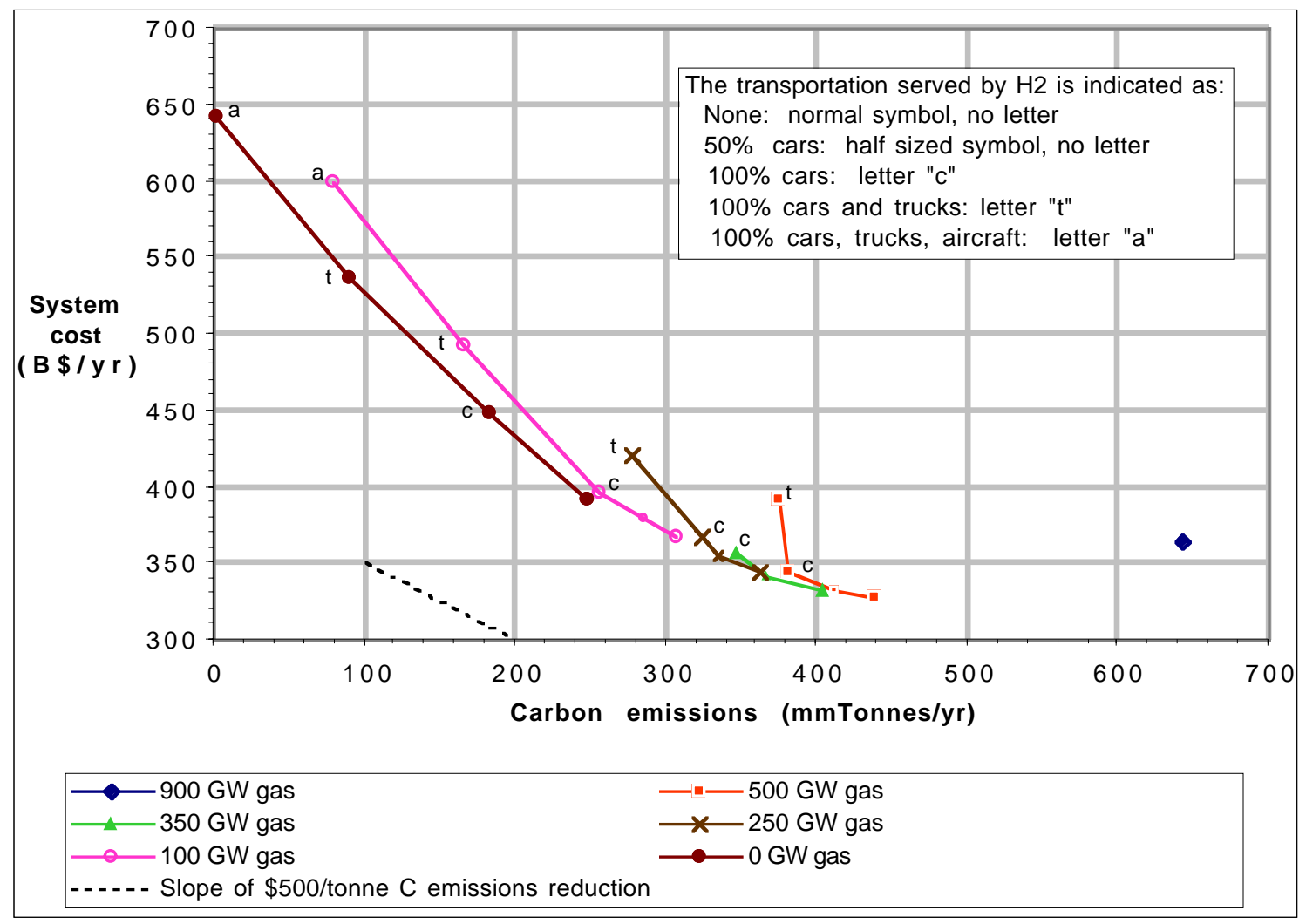

Figure 6: Additional scenarios showing the impact of hydrogen fueled transportation to electricity and transportation emissions and costs along the efficient frontier.

The comparable costs of utility and transportation carbon reductions in this regime are principally driven by the projected higher efficiency of gas-fired combined cycle plants relative to peak power hydrogen fuel cells. Renewable hydrogen in utility energy storage can reduce more emissions by fueling light-duty vehicles than powering fuel cells. From the perspective of efficiently using natural gas, natural gas is more efficient than hydrogen at providing grid electricity while only equally efficient as a transportation fuel. In addition to improving carbon reduction efficiency, the flexibility of combined hydrogen storage and vehicle refueling can improve overall system capital and energy efficiency through higher capacity factors for renewable sources and fossil fuel capacity.

There is substantial value in maintaining approximately $20 \%$ of capacity as dispatchable technologies - costs begin to rise steeply as the last $100 \mathrm{GW}$ of gas-fired capacity is eliminated from the utility system (Figure 6), especially in cases with hydrogen transportation. Retaining about $20 \%$ dispatchable capacity minimizes the need for energy intensive storage. Strategically, this permits a broader array of complementary emission 
reduction technologies to be implemented earlier rather than later. Sequestration of modest gas-fired (potentially biomass) generation, in concert with transportation emission reductions from hydrogen fuel, can result in emissions levels (182mmtC/yr) well below those achievable by renewable utilities alone, and probably at lower overall costs than a strictly non-fossil approach to utilities and transportation.

\subsection{Alternatives to hydrogen energy storage}

In the scenarios discussed earlier only cryogenic and compressed hydrogen energy storage were used, principally due to very low capital costs $(\$ 0.30 / \mathrm{kWh}$ for cryogenic liquid hydrogen and $\$ 4.50 / \mathrm{kWh}$ compressed hydrogen), in spite of roundtrip efficiencies of only 30-40\%. Figure 5 shows the significant energy losses ( 20\%) attributable to hydrogen storage and reconversion to electricity. Higher efficiency electricity storage alternatives (e.g. flywheels) could dramatically reduce these losses.

Additional scenarios (Table 1) exploring the potential of higher efficiency storage indicate that even $100 \%$ efficient electricity storage, an optimistic approximation of flywheels or batteries, would only become cost effective at less than $\$ 100 / \mathrm{kWh}$ as long as some dispatchable (e.g. natural gas) capacity remains in the electricity mix. Flywheels become more cost effective if fossil electric generation is eliminated entirely, and especially in cases with large solar electricity peaks and hydrogen transportation sectors. Flywheels, or any high efficiency electric storage, approaches a value of $\sim \$ 200 / \mathrm{kWh}$ of storage in this most favorable case. These cost levels may be ultimately achievable through higher performance, lower cost fiber-based composite materials. However, such advances in materials, may also reduce the costs of composite pressure vessels used to store compressed hydrogen.

Table 1: Break-even capital costs (at 5\% discount rate) for notional 100\% efficient flywheel storage in selected scenarios from Figure 6.

\begin{tabular}{|l|c|l|l|l|l|l|l|c|}
\hline \multicolumn{4}{|c|}{ System description } & \multicolumn{5}{c|}{ Analysis results } \\
\hline $\begin{array}{l}\text { Trans- } \\
\text { portation } \\
\text { demand } \\
\text { served }\end{array}$ & $\begin{array}{l}\text { Fossil } \\
\text { cap- } \\
\text { acity } \\
\text { (TW) }\end{array}$ & $\begin{array}{l}\text { Nuclear } \\
\text { cap- } \\
\text { acity } \\
(\mathrm{TW})\end{array}$ & $\begin{array}{l}\text { Fly } \\
\text { wheel } \\
\text { cap- } \\
\text { acity } \\
(\mathrm{TWh})\end{array}$ & $\begin{array}{l}\text { System } \\
\text { cost w/o } \\
\text { fly wheel } \\
(\$ \mathrm{~B} / \mathrm{yr})\end{array}$ & $\begin{array}{l}\text { system cost } \\
\text { with flywheel } \\
\text { (excluding } \\
\text { cost of } \\
\text { flywhel } \\
\text { itself) }(\$ \mathrm{~B} / \mathrm{yr})\end{array}$ & $\begin{array}{l}\text { Annual } \\
\text { cost } \\
\text { savings } \\
(\$ \mathrm{~B} / \mathrm{yr})\end{array}$ & $\begin{array}{l}\text { Annual } \\
\text { cost } \\
\text { savings } \\
\text { per kWh } \\
\text { storage }\end{array}$ & $\begin{array}{l}\text { Equivalent } \\
\text { capital } \\
\text { cost of } \\
\text { savings, } \\
(\$ / \mathrm{kWh})\end{array}$ \\
\hline None & 0.5 & 0.10 & 10 & 326.7 & 309.7 & 17.1 & 1.71 & 21.3 \\
None & 0.1 & 0.10 & 5 & 367.7 & 341.7 & 26.0 & 5.19 & 64.7 \\
None & 0.0 & 0.10 & 5 & 391.1 & 361.9 & 29.2 & 5.84 & 72.8
\end{tabular}




\begin{tabular}{|l|l|l|l|l|l|l|l|l|}
$\begin{array}{l}\text { Cars, } \\
\text { trucks }\end{array}$ & 0.0 & 0.10 & 5 & 536.3 & 455.8 & 80.5 & 16.09 & 200.6 \\
\hline
\end{tabular}

\subsection{Hydrogen vehicles as buffer energy storage}

In addition to the use of flywheels, energy efficiency can also be improved by using short-term compressed hydrogen storage over energy intensive storage as a cryogenic liquid. Additional short term storage capacity is potentially available within the transportation sector itself. All the scenarios modeled (Figure 6) in this chapter essentially take no credit for hydrogen storage onboard vehicles, using instead the conservative assumption that a future hydrogen transportation sector would have patterns of refueling identical to present fossil fueled transportation. This may not necessarily be the case. One intriguing possibility is the potential for energy consumers in a hydrogen transportation sector to adjust refueling and travel patterns, and perhaps end-use efficiency (speed), in response to near term and seasonal hydrogen supply levels. A responsive transportation sector could significantly impact renewable utilities. Fueling hydrogen transportation can account for $20-50 \%$ of electricity generation, and the hydrogen onboard vehicles at any given time is 2-4 times the amount in short term utility storage. If transportation demand turns out to be flexible, this could then buffer utility storage, improving hydrogen storage efficiency, perhaps ameliorating seasonal requirements for long-term cryogenic storage. Going one step further, some have proposed using fuel cell passenger vehicles as backup utility storage, noting that the generation capacity of parked vehicles in the United States would be on the order of 20 times the projected U.S. generating capacity.

\subsection{Strategies for reducing carbon emissions}

In conclusion it appears that after end-use efficiency improvements are made, a robust carbon reduction strategy should prepare to follow a dual sector approach, making use of wind, solar, and a small but vital amount of dispatchable electric generation. While hydrogen storage and fuel cell systems can enable carbonless electric generation, hydrogen fueled transportation, especially light-duty vehicles, can also contribute effectively to carbon reduction, especially if consumers choose to impact emissions through more flexible transportation decisions. Hydrogen transportation complements a modest sequestration effort, should it be warranted, by essentially shifting transportation emissions to large scale utility generation facilities. A strategy composed of these elements can cost-effectively eliminate the bulk of carbon emissions from these sectors, while commercializing the technologies necessary to ultimately eliminate carbon emissions. Energy storage as both cryogenic liquid and compressed hydrogen are likely to be cost effective, even more so in tandem with hydrogen vehicles. Very high efficiency utility power storage technologies (e.g. flywheels) will need to be very low cost (less than 
$\$ 100 / \mathrm{kWh}$ ) in order to provide substantial benefit, although the their value is greater in solar dominated energy systems.

Looking beyond the largely linear combination of transportation and utility sectors explored in these analyses, there may be further synergies to be gained by carefully integrating energy technology and use patterns, developing a more complex and interdependent relationship between electricity and hydrogen fuel production. Excess heat from gas fired generation and perhaps hydrogen fuel cells could improve the efficiency of steam electrolysis. Pure oxygen, the byproduct of electrolytic hydrogen, would also enable improved electric generation with natural gas, in fuel cells, if not in combined cycle plants. Even further ahead, the functions of fuel cell, electrolyzer, and hydrogen compressor may be combined in a single electrochemical device, improving thermal integration and electric network topology possibilities substantially. The key technology throughout is that which links electricity and transportation fuel, efficient hydrogen production by electrolysis. 


\section{References}

Aceves, S.M. et al. 1998. "Onboard Storage Alternatives for Hydrogen Vehicles”. Energy and Fuels, Vol. 12, No. 1 pp. 49-55.

Andersson, B. and Rade, I., 1998. "Large Scale Electric Vehicle Battery Systems: LongTerm Material Constraints". $4^{\text {th }}$ International Battery Recycling Congress (IBRC). Hamburg, Germany.

Berry, G., 1996. "Hydrogen as a Transportation Fuel: Costs and Benefits". Lawrence Livermore National Laboratory report UCRL-ID-123465.

Bockris, J., 1980. "Energy Options: Real Economics and the Solar-Hydrogen System". Australia and New Zealand Book Company, Sydney.

CRC Press, 1977. "Hydrogen:Its Technology and Implications". Volumes 1-5. Cleveland Ohio.

De Laquil III, P. et al, 1990. "Solar Central Receiver Technology Improvements over Ten Years", Solar Thermal Technology - Research Development and Applications.

Hemisphere Publishing Corporation.

Energy Information Agency. 2000. "Annual Energy Outlook 2000". Washington DC.

Fetter, S., 1999. "Climate Change and the Transformation of World Energy Supply". Center for International Security and Cooperation, Stanford University, Stanford CA.

Gordon, S.P. and Falcone, P.K., 1995. "The Emerging Roles of Energy Storage in a Competitive Power Market: Summary of a DOE Workshop". Sandia National

Laboratories, SAND95-8247.

Halmann, M. and Steinberg, M., 1999. "Greenhouse Gas Carbon dioxide Mitigation Science and Technology",.Lewis Publishers, Boca Raton.

Hassol, S. and Katzenberger, J., 1998. "Impacts of Energy Use on Global Biospheric Cycle. Vaclav Smil in Elements of Change 1998", Aspen Global Change Institute, Aspen CO 81611.

Hoffert, M., 1998. "Technologies for a Greenhouse Planet", Elements of Change, Aspen Global Change Institute, Aspen CO 81611

Iannucci, J. et al. 1998. "Coupling Renewables via Hydrogen into Utilities: Temporal and Spatial Issues, and Technology Opportunities". Distributed Utility Associates Livermore, CA 
Ingersoll, J.G., 1991. "Energy Storage Systems", The Energy Sourcebook: a Guide to Technology, Resources, and Policy. American Institute of Physics, New York.

Intergovernmental Panel on Climate Change, 1996. "Technologies, Policies and Measures for Mitigating Climate Change."

Kelly, H. and Weinberg, C.J., 1993. "Utility Strategies for Using Renewables", Chapter 23 in Renewable Energy: Sources for Fuels and Electricity, Island Press, Washington D.C.

Ogden, J. and Nitsch, J., 1993. "Solar Hydrogen", Renewable Energy: Sources for Fuels and Electricity, Chapter 22, Island Press, Washington D.C

Ogden, J. and Williams, R., 1989. "Solar Hydrogen: Moving Beyond Fossil FuelsWorld", Resources Institute Washington D.C.

Post, R.F. et al, 1993. "A High Efficiency Electromechanical Battery”. Proceedings of the IEEE Vol 81. No. 3 pp. 462-474.

Post, R.F. and Post S.F., 1973 "Flywheels" Scientific American Vol 229 Number 6 pp 1723.

Schipper, L. and Meyers, S., 1992. "Energy Efficiency and Human Activity: Past Trends and Future Prospects". Cambridge University Press.

Union of Concerned Scientists, 1992. "America's Energy Choices: Investing in a Strong Economy and a Clean Environment," Cambridge MA.

Vakil, H.B. and Flock, J.W., 1978. "Closed Loop Chemical Energy Systems for Energy Storage and Transmission (Chemical Heat Pipe) Final Report". Power Systems Laboratory, Corporate Research and Development, General Electric Company Schenectady, New York. Performed for U.S. Department of Energy, Division of Energy Storage Systems.

Winter, C.J. and Nitsch, J., 1988. "Hydrogen as an Energy Carrier". Springer Verlag Berlin. 
Appendix A:: Economic and Technical Assumptions Used in Model Scenarios (2020 United States Electricity and Transportation Fuel Sectors)

\section{Energy Demand}

Annual end-use electric demand

Annual transportation fuel demand

Light Duty Vehicles

Freight Transport

Aircraft
5.066 Trillion kWh

4.589 Trillion $\mathrm{kWh}$

1.254 Trillion $\mathrm{kWh}$

1.697 Trillion kWh

1.638 Trillion $\mathrm{kWh}$

\section{Primary Energy Supply}

Transportation Delivered Natural Gas Price

Utility Natural Gas Price

Reference Case Annual Gas Consumption

Annual Solar Capacity Factor

Annual Wind Capacity Factor

Maximum Wind Capacity

Nuclear/Hydro Capacity
$\$ 6.93-8.31 / \mathrm{GJ}$

$\$ 5.54 / G J$

$43 \mathrm{EJ} / \mathrm{yr}$

$29.5 \%$

$43.3 \%$

$1.0 \mathrm{TW}$

$0.1 \mathrm{TW}$

\section{Economic and Environmental}

Discount Rate

Natural gas emission factor (combustion)

Fuel cycle emissions (production, compression, leakage)
$5 \%$

$54 \mathrm{~g} \mathrm{C} / \mathrm{kWht}$

neglected 


\section{Electric Generation Technology Assumptions}

Nuclear Fission

Life

Operating cost

Combined Cycle Plant

Life

Non-fuel operating cost

Efficiency

Wind

Life

Solar Photovoltaic

Life

Fuel Cells (peak)

Life

Efficiency (LHV hydrogen)
$\$ 2200 / \mathrm{kW}$

40 years

1 cent $/ \mathrm{kWh}$

$\$ 600 / \mathrm{kW}$

30 years

0.5 cents/kWh

$57 \%$

$\$ 655 / \mathrm{kW}$

15 years

$\$ 1500 / \mathrm{kWp}$

30 years

$\$ 200 / \mathrm{kW}$

20 years

$50 \%$

Electric Transmission and Distribution

$\$ 200 / \mathrm{kW}$

Life
30 years

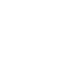




\section{Hydrogen Production and Storage Technology Assumptions}

Steam Electrolysis (baseload)

Life

Efficiency (LHV)

Steam Electrolysis (peak)

Life

Efficiency (LHV)

Hydrogen Compression

Life

Efficiency (LHV)

Maintenance

Compressed Hydrogen Storage (5000 psi)

Life

Hydrogen Liquefier

Life

Efficiency

Maintenance

Liquid Hydrogen Storage (Large Scale)

Life
$\$ 500 / \mathrm{kW}$

20 years

$91 \%$

$\$ 250 / \mathrm{kW}$

20 years

$83 \%$

$\$ 100 / \mathrm{kW}$

15 Years

$91 \%$

0.1 cent $/ \mathrm{kWh}$

$\$ 4.50 / \mathrm{kWh}$

20 years

$\$ 500 / \mathrm{kW}$

20 years

$71 \%$

0.1 cents/kWh

$\$ 0.30 / \mathrm{kWh}$

20 Years 


\section{Appendix B: Overview of the model system}

To conduct these studies we modeled an energy system potentially drawing on a range of resources, both conventional and renewable, and supplying electricity and transportation fuels. The model can be set up to represent an entirely conventional system, a system that relies entirely on renewable energy, or any mixture. When modeling a renewable system, the model includes a fuel cell to cover peak electric demands. In these analyses the system was always configured to reliably serve the electric load.

The technological parameters (efficiencies and costs) represent a system that might be developed some decades in the future (see Table 2 for cost and performance assumptions). We have used optimistic estimates of the costs and efficiencies of various technologies including natural gas technologies, since this should give a more useful picture of the tradeoff between these technologies in a future context.

Figure 1 (chapter text) shows a system schematic. The primary resources are wind, solar, nuclear, and a gas fired turbine. A fuel cell is provided with enough capacity to cover the electric demand if the wind and solar are not sufficient. This is sized to just cover the maximum shortfall, not the maximum electric demand. A flywheel storage option is also included in some of the runs. This can take electricity from the grid and return it later. The hydrogen transportation fuel sector is modeled directly within the model. These analyses evaluate various scenarios on the fraction of transportation fuel that is met by hydrogen. It is assumed that the balance of the transportation fuel is provided by natural gas. The costs and emissions from the natural gas fueled transportation are included in final cost and emissions results.

Both compressed hydrogen and liquid hydrogen storage have been included, along with the compression and liquefaction capacity needed to provide their outputs. For given capacities of long and short-term storage, the model determines the rates of filling and discharge for each of the storage devices each hour to minimize the overall cost. The model determines the required level of long-term storage capacity. Short-term storage capacity is varied based on the assumptions about wind and solar capacities and the transportation fuel demand.

\section{Analysis method}

Each scenario analyzed in this chapter required the optimization of both the system structure and annual operations under a set of constraints. The system structure is defined by the capacities of each of the components (e.g. generators, electrolyzers, storage, compressors, etc.). The system operations specify exactly how each component 
will be dispatched hour-by-hour over the year. This includes the allocation of electric demands to the generators each hour and the allocation of hydrogen production between the two electrolyzers. The storage devices must also allocate their purchases of hydrogen over time so as to meet their demands at the lowest cost.

Several constraints must be observed in the solution: the total demands for electricity and hydrogen must be met, and in most cases the maximum capacities of specific generating technologies were constrained. Once the capacity of a given generating unit is set, its production each hour is constrained. For the dispatchable technologies (the natural gas turbine and the nuclear generator) the constraint is constant each hour. For the renewable technologies the constraint each hour is a function of the capacity of the generator and the resource availability in each hour.

This requires a bi-level optimization approach: both the structure of the system must be optimized and the operation of the system, given the structure, must be optimized. We have extended the META $\bullet$ Net economic modeling system (Lamont, 1994) to make these analyses. META $\bullet$ Net is a software system that allows the user to structure and solve models of economic systems. The system is modeled as a network of nodes representing end-use demands, conversion processes (such as generation or storage), markets, and resources. The markets represent the points in the system where a total demand (e.g. for electricity) will be allocated among a set of suppliers. META $\bullet N e t$ finds a set of allocations each hour that is an economic equilibrium-all the demands are met and each market is in equilibrium.

META $\bullet$ Net finds the equilibrium solution through a series of iterations. Each iteration consists of a down pass and an up pass. On the down pass, the end-use demand nodes (here they are electric demand and demands for hydrogen transportation fuels) pass their demands down to the next nodes. When a node receives a demand it determines how to supply that demand. Market nodes sum up the total demand each period and then allocate that demand to all of its suppliers based on the prices that the suppliers require in that period. Conversion nodes determine the amount of each input they require in order to produce the demand. A conversion node may have several inputs. For example a hydrogen compressor produces compressed hydrogen from uncompressed hydrogen using both hydrogen and electricity. They then pass the demands for the required inputs down the network to the nodes that provide those inputs.

Eventually the demands are passed down to the resource nodes. At this point the up-pass starts. The resource nodes determine the price (marginal cost) that must be charged in order to meet the demand. They then pass this price back up the network. When a conversion node receives the prices for its inputs, it computes the price required for its output including any capital or other operating costs. All nodes set prices to meet a target 
rate of return. These prices eventually are passed up to the end-use demand nodes. In general META $\cdot$ Net allows for price sensitive demands, however in this case the demands are fixed each hour. Through a series of iterations the allocations at the market nodes are adjusted until the total quantity demanded each hour is in equilibrium with the prices charged each hour. Further, the allocations within the market node are made until the prices (i.e. marginal costs) from the suppliers are equalized.

The economic equilibrium solution is equivalent to a cost minimization solution. Hogan and Weyant (1982) provide the formal proof of the equivalence between the equilibrium and cost optimization solutions for these sorts of network models. Intuitively the equivalence can be seen as follows: Each of the production nodes determine their marginal cost of production each hour given the demands for output that they see. The market nodes allocate demand to each of the suppliers such that the marginal costs of production between the competing suppliers are equalized. The storage nodes are somewhat like market nodes, in that they have a total demand for releases-or "production" - over time. They attempt to minimize costs by purchasing this total amount at the hours when costs are minimum. The algorithm for the storage node also equalizes the marginal costs of purchases over time periods. In fact, correctly modeling the optimal operation of storage devices is very compute intensive. The algorithm used in this version of META $\cdot N e t$ is an approximation to the true optimum. Through side calculations we find that the resulting system cost is within a percent or two of the true minimum cost.

\section{Constraints}

The renewable technologies have constraints in each hour, reflecting the hourly availability of the resource and the capacity that has been set. Each of the dispatchable technologies also have constraints reflecting the actual capacity available. These constraints are enforced by computing shadow prices whenever the demand to a node exceeds its constraint. The market allocations are actually based on these shadow prices. The shadow prices are adjusted until the constraints are just met.

\section{Capacity modeling}

The discussion above describes the optimization of operation and dispatch for each hour of the year. The model also optimizes the capacities of the components. The capacities are adjusted each iteration, but once they are set, they are constant for the entire year. Essentially, the capacities are adjusted until the marginal value of capacity is equal to the marginal cost of additional capacity. Note that we can also place maximum constraints on the capacity for any node. 


\section{References for Appendix B}

Hogan, William W. and John P. Weyant, (1982), "Combined Energy Models", in Advances in the Economics of Energy and Resources, Vol. 4, pages 117-150, JAI Press Inc.

Lamont, A., User's guide to the META-Net Economic Modeling System; version 1.2, Lawrence Livermore National Laboratory, UCRL-ID-122511, 1994 